\title{
MUDANÇAS NA BIOMASSA MICROBIANA E NAS TRANSFORMAÇÕES DE NITROGÊNIO DO SOLO EM UMA SEQÜÊNCIA DE IDADES DE PASTAGENS APÓS DERRUBA E QUEIMA DA FLORESTA NA AMAZÔNIA CENTRAL.
}

\author{
Regina C. C. LUIZÃo, Enir Salazar COSTA, Flávio J. LUIZÃo
}

RESUMO - Foram estudadas mudanças nos parâmetros bioquímicos do solo em resultado da derruba e queima da floresta tropical na Amazônia brasileira para o estabelecimento de pastagens através da biomassa microbiana, um sensível indicador de modificaçôes na fertilidade do solo. Na sequiência de idades das pastagens estudadas (de 2 a 13 anos), a biomassa microbiana e a respiração na camada superficial de $0-5$ $\mathrm{cm}$ do solo aumentaram até os cinco anos após o estabelecimento da pastagem, seguindo-se um declinio progressivo, que se acentua após o oitavo ano da pastagem. As baixas taxas de mineralização do nitrogênio no solo sugerem que o estoque de $\mathrm{N}$ orgânico está diminuindo, o que pode levar a deficiências de nitrogênio nos solos das pastagens mais velhas. A massa total de raizes nos primeiros $20 \mathrm{~cm}$ do solo diminuiu drasticamente com a idade da pastagem. A relação $\mathrm{C} / \mathrm{N}$ das raizes finas na pastagem foi mais elevada do que na floresta madura. Isto pode indicar a formação, pela gramínea da pastagem, de uma matéria orgânica com potencial mais baixo de liberação de nutrientes minerais do que a originalmente produzida pela floresta, o que pode estar contribuindo para a baixa produtividade das pastagens a médio prazo e para sua posterior degradação. O periodo de 5 anos de pousio após o abandono ainda foi curto para recuperar um solo de pastagem usada moderadamente para pastejo por cerca de 4 anos.

Palavras chave: biomassa microbiana; mineralização do nitrogênio orgânico; pastagens; degradação dos solos.

Changes in Microbial Biomass and in Soil Nitrogem Transformations in a Sequence of Pastures with Different Ages after Slash and Burning of a Forest in Central Amazonia.

ABSTRACT - Changes in biochemical parameters of a soil from a tropical Brazilian forest slashed and burned for establishment of pastures were estimated through microbial biomass, a sensitive indicator of changes in soil fertility. In a chronological sequence of pastures ( 2 to 13 years), microbial biomass and soil respiration of topsoil $(0-5 \mathrm{~cm})$ increased with the age up to the fifth year after pasture establishment, followed by a progressive decline, which was prominent after the eighth year as pasture. Lower nitrogen mineralization rate was found in these soils suggesting that nitrogen stock may be decreasing, which can lead to nitrogen defficiency in older pasture soils. Root mass in the first $20 \mathrm{~cm}$ of soil drastically decreased when pastures were established. The $\mathrm{C} / \mathrm{N}$ ratio in fine roots was greater in the pasture than in the primary forest. This could indicate the formation, by the pasture grass, of a soil organic matter with less potencial of nutrient mineralization, which eventually can contribute to the low pasture productivity in the medium term and its posterior degradation. A five-year period of fallow after pasture abandonment seemed to be too short for the recovery of a soil used for grazing of moderate intensity during four years.

Key-words: Microbial Biomass; Old Pastures; Nitrogen Mineralization

\section{INTRODUÇÃO}

A população microbiana do solo, que engloba fungos, bactérias, algas e a microfauna, atua como um catalisador das importantes transformações químicas no solo e, consequentemente, desempenha um papel essencial no funcionamento dos ecossistemas (Powlson et al., 1987; Bonde et al., 1988). A biomassa microbiana mineraliza tanto os residuos orgânicos recentes como a matéria

Coordenação de Pesquisas em Ecologia, Instituto Nacional de Pesquisas da Amazônia, Caixa

Postal 478, 69011-970, Manaus, AM. 
orgânica pré-existente no solo.

Em ecossistemas naturais da Amazônia, tal como a floresta de terra firme, a fertilidade do solo é inteiramente dependente do aporte de nutrientes advindos da atmosfera e de sua própria biomassa vegetal, uma vez que as entradas de novos nutrientes da rocha-mãe são negligiveis (Schubart et al., 1984). Os residuos vegetais, ao cairem sobre o solo, são submetidos aos processos microbianos que oxidam e finalmente liberam nutrientes essenciais $(\mathrm{C}, \mathrm{N}, \mathrm{P}, \mathrm{S})$ à nutrição da biota do solo e das plantas (Jenkinson \& Ladd, 1981; Saggar et al., 1981; Brookes et al., 1985). Em grande parte, é por se desconsiderar tais processos naturais que atualmente existem, na região amazônica, grandes áreas degradadas e improdutivas. Por exemplo, em 1987 foi estimado que $3,5 \times 10^{6}$ ha de floresta tropical da Amazônia brasileira já havia sido cortada (Fearnside, 1989), a maior parte dela para o estabelecimento de pastagens. Conforme previsto, a maioria dessas pastagens tornaram-se improdutivas após alguns anos de uso (Teixeira \& Bastos, 1989), uma possível conseqüência do declínio no estoque e na qualidade da matéria orgânica do solo. Qualquer manejo que suprima ou afete a população microbiana e de outros organismos do solo, ou que mude a qualidade ou quantidade da matéria orgânica, pode causar danos ao funcionamento do sistema solo-planta, quer a curto prazo ou por um período maior (Brookes \& Verstraete, 1989).

O nitrogênio $(\mathrm{N})$ é um dos principais nutrientes que limita a produtividade nos sistemas agrícolas e agrossilviculturais introduzidos após a derruba da floresta natural. À parte do $\mathrm{N}$ disponibilizado pela fixação biológica ( $\mathrm{N}_{2}$ fixado do ar por bactérias), a maioria do $\mathrm{N}$ utilizado pelas plantas em ecossistemas sobre solos pobres é derivado da decomposição da matéria orgânica. Portanto, a perda generalizada de matéria orgânica durante a conversão da floresta em pastagem é crucial na perda subsequente da fertilidade do solo, incluindo problemas de baixa mineralização do $\mathrm{N}$.

No final dos anos 80 , foi iniciado um estudo de médio a longo prazo com o objetivo de avaliar as mudanças na dinâmica da biomassa microbiana e suas atividades no solo após a conversão da floresta em pastagens. Também foi estudada sua influência nos processos de mineralização do carbono e nitrogênio na camada superficial do solo (de 0-20 cm) em uma seqüência de pastagens de diferentes idades $(2,5$, $6,7,8,12$ e 13 anos). Adicionalmente, evidências da recuperação desses parâmetros bioquímicos do solo foram investigadas num gradiente pastagem abandonada-pousio-floresta.

\section{MATERIAL E MÉTODOS}

\section{Localização e Caracterização das Áreas de Estudo}

Entre 1987 e 1993, foram estudadas várias pastagens em diferentes estádios de uso, degradação e/ou abandono (pousio) no município de Manaus. Todas elas situavam-se em duas estações experimentais próximas entre si: FazendaModelo da FUCADA/SUFRAMA (Fundação Centro de Apoio ao Distrito Agropecuário/Superintendência da Zona Franca de Manaus), localizada no km 
38 da rodovia Manaus-Boa Vista (BR174 , coordenadas $2^{\circ} 33^{\prime} \mathrm{S}$ e $60^{\circ} 02^{\prime} \mathrm{W}$ ), e no Campo Experimental de Zootecnia da EMBRAPA (Empresa Brasileira de Pesquisa Agropecuária, coordenadas $2^{\circ} 30^{\prime} \mathrm{S}$ e $60^{\circ} 02^{\prime} \mathrm{W}$ ), no $\mathrm{km} 54$ da mesma rodovia.

O clima da região que engloba as áreas de estudo é do tipo $\mathrm{Am}$ na classificação de Köppen, pertencendo ao grupo de clima tropical chuvoso (Ribeiro \& Adis, 1984). Neste tipo climático, praticamente inexiste um período de estiagem, evidenciando-se a distribuição das chuvas em duas estações bem distintas, sendo uma com excesso de precipitação pluviométrica e outra com chuvas mais suaves e esparsas (Fig. 1). As temperaturas médias anuais oscilam entre $26-27^{\circ} \mathrm{C}$, com pouca variabilidade no regime térmico da área (Ribeiro \& Adis, 1984).

Os solos de ambas as estações são similares (Grimaldi et al., 1992) e classificados como Latossolos Amarelos muito argilosos, onde são encontradas limitações de fertilidade, acidez elevada, baixa capacidade de troca de cátions, deficiências de fósforo, cálcio e magnésio, e pHácido (geralmente <4,2) (Teixeira \& Bastos, 1989).

Todas as pastagens foram plantadas, após a derruba manual e queima da floresta, com a graminea Brachiaria humidicola Rendle, sem uso de fertilizantes quimicos, exceto para a pastagem mais jovem da FUCADA. Esta pastagem, em seus dois primeiros anos de vida, recebeu cinco adubações à base de NPK, duas das quais foram feitas em 1987. Na primeira destas (em fevereiro/87), foram utilizados $25 \mathrm{~kg}$ de uréia, $100 \mathrm{~kg}$ de superfosfato triplo e $25 \mathrm{~kg}$ de cloreto de potássio ( $65 \mathrm{~kg} / \mathrm{ha})$; na segunda (em junho/87), foram utilizados $15 \mathrm{~kg}$ de uréia, $50 \mathrm{~kg}$ de superfosfato triplo, $50 \mathrm{~kg}$ de fósforo

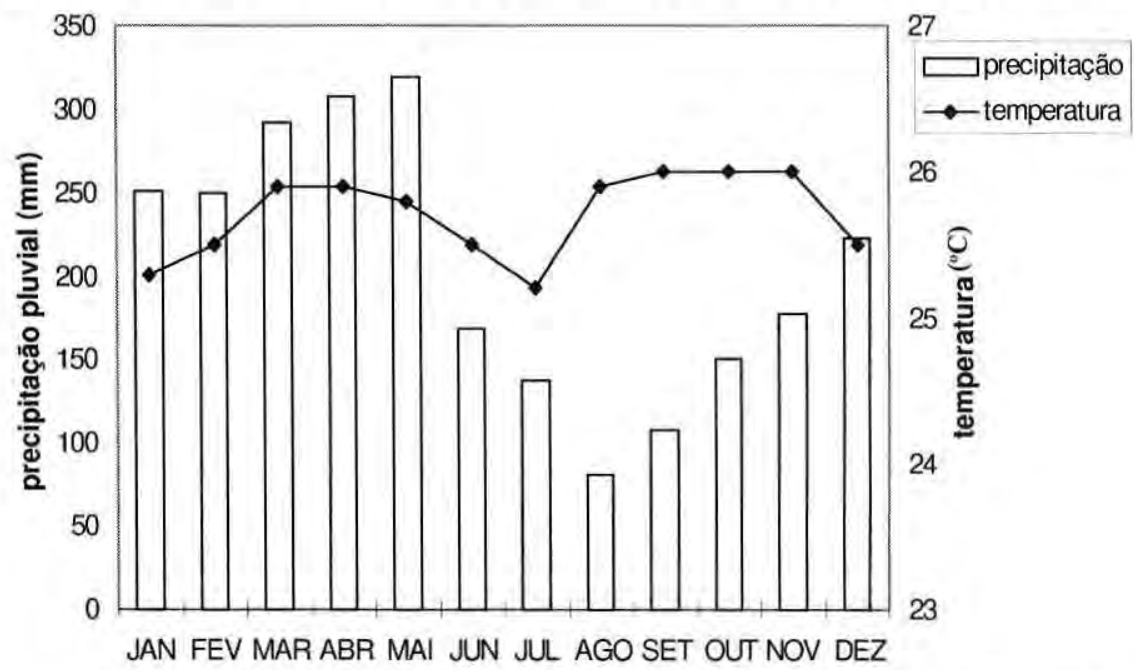

Figura 1. Médias mensais da precipitação pluvial $(\mathrm{mm})$ e da temperatura do ar $\left({ }^{\circ} \mathrm{C}\right)$ nas áreas da EMBRAPA e FUCADA, no periodo de 10 anos, de 1981 a 1991 (Fonte: Mackerrow, 1992). A média anual de precipitação pluviométrica é de $2100 \mathrm{~mm}$ (Ribeiro \& Adis, 1984). 
bicálcico e $15 \mathrm{~kg}$ de cloreto de potássio $(50 \mathrm{~kg} / \mathrm{ha})$. O pastejo ocorreu em sistema de rodízio, com média de vinte dias de uso e vinte dias de descanso, aproximadamente da mesma forma que ocorria nas pastagens da EMBRAPA (Teixeira \& Bastos, 1989).

\section{Seqüência de Estudos Comparativos}

Durante o ano de 1987, foram realizadas coletas mensais de solo, para se comparar a biomassa microbiana, a massa de raizes finas e a mineralização de $\mathrm{Ce} \mathrm{N}$, entre uma floresta original, uma área recém-queimada e uma pastagem jovem ( 2 anos de idade). Este estudo foi feito na Fazenda-Modelo da FUCADA. No ano de 1990 , realizaram-se duas coletas, uma na estação seca e outra na chuvosa, comparando-se os mesmos parâmetros bioquimicos acima, na pastagem "jovem" da FUCADA (então com 5 anos de idade) e duas pastagens mais velhas na EMBRAPA (então com 7 e 12 anos de idade). No ano seguinte (1996), da mesma forma, repetiram-se as coletas nas pastagens da FUCADA (então com 6 anos) e da EMBRAPA (então com 8 e 13 anos de idade, respectivamente). Neste ano (1991), a pastagem mais velha da EMBRAPA (com 13 anos) foi abandonada, devido à sua baixa produtividade e avançado estádio de degradação. Nos anos de 1992-1993, na EMBRAPA, foram comparadas a pastagem abandonada em 1991 (então com 1,5-2 anos de abandono), uma área próxima de pousio (5-6 anos após o abandono da pastagem) e uma área de floresta madura, usada como controle. A pastagem abandonada já apresentava algumas moitas de vegetação secundária em crescimento, cobrindo cerca de $15 \%$ de sua área total. O pousio apresentava uma cobertura arbórea já cobrindo cerca de $75 \%$ de sua área total. Os gêneros predominantes foram Vismia, Lactea e Casearea (C. Yano, dados não-publicados).

\section{Metodologia de Coleta no Campo, Tratamento Inicial das Amostras e Análises}

Em todas as amostragens feitas, exceto nas dos anos 1992-1993, seguiu-se o mesmo procedimento para a coleta das amostras de solo. Em cada ecossistema, foram traçadas duas linhas paralelas de aproximadamente trinta metros, distante cerca de dez metros uma da outra, com três pontos de amostragem no início, meio e fim de cada uma. Em cada ponto, foram coletadas aproximadamente $500 \mathrm{~g}$ de solo, separadamente das profundidades de $0-5$ $\mathrm{cm}$ (sem liteira) e de $5-20 \mathrm{~cm}$, com o auxilio de uma faca e uma pá. As amostras eram colocadas em sacos plásticos e transportadas em caixa de isopor até o laboratório onde eram deixadas numa incubadora a $24^{\circ} \mathrm{C}$ até o dia seguinte e, então, submetidas à remoção manual das raizes, pedras, carvão e invertebrados visiveis a olhos nu. Nas coletas realizadas na EMBRAPA em 1992-1993, foram demarcadas três parcelas de $10 \mathrm{~m} \times 10 \mathrm{~m}$ em cada sistema estudado (pastagem abandonada, pousio e floresta). Em cada parcela foram coletadas aleatoriamente cinco amostras compostas de solo na profundidade de $0-10 \mathrm{~cm}$, com o auxilio de uma faca e uma pá pequena; as subamostras (cinco) foram coletadas sempre em pontos próximos, dentro de um raio de $2 \mathrm{~m}$, como meio de minimizar a alta 
variabilidade espacial do solo (Correia \& Reichardt, 1989). As amostras compostas foram tratadas individualmente $\mathrm{e}$ consideradas réplicas entre si.

No estudo comparativo entre a pastagem, área queimada e floresta da FUCADA, as raizes do solo foram coletadas em quatro ocasiões distintas no periodo de um ano (janeiro/87 a janeiro/ 88), sendo uma coleta feita na parte média final da estação chuvosa (abril), outra na parte média final da estação seca (outubro) e duas no início da estação chuvosa (janeiro de 1987 e 1988). Foram escavados seis quadrados de $20 \mathrm{~cm} \times 20 \mathrm{~cm}$, recolhendo-se separadamente o solo e raizes das profundidades de $0-5 \mathrm{~cm}$ e 5 $20 \mathrm{~cm}$. No laboratório, as raizes foram lavadas com jatos de água corrente, em peneiras de malha fina $(0,5 \mathrm{~mm})$, separadas em três classes, de acordo com seu diâmetro (finas: < $1 \mathrm{~mm}$; médias: 1 a 5 $\mathrm{mm}$; grossas: $>5 \mathrm{~mm}$ ), secas e pesadas individualmente.

A biomassa microbiana foi determinada pelo método da FumigaçãoIncubação (FI) de Jenkinson \& Polwson (1976) adaptado para solos ácidos (Vance et al., 1987). O carbono orgânico do solo foi determinado pelo método Walkley \& Black (Jackson, 1958). O pH do solo foi determinado em água destilada numa suspensão $1 \mathrm{M} \mathrm{KCl}$. A atividade biológica do solo foi medida pela taxa de respiração do solo incubado por dez dias.

As medidas das concentrações de N$\mathrm{NH}_{4}^{+}$e N-NO${ }_{3}$ do solo foram feitas após extração com cloreto de potássio $(\mathrm{KCl})$. Os ions de $\mathrm{N}^{-\mathrm{NH}^{+}}{ }_{4}$ foram determinados pelo método do azul de indofenol (Runge, 1971) adaptado para fluxo contínuo (Jorgensen, não-publicado) e os do N-
$\mathrm{NO}_{3}$ pelo método da redução por cobre em fluxo contínuo (Giné et al., 1980). As concentrações de carbono nas raizes foram determinadas por combustão seca num analisador Whösthof e o nitrogênio nas raizes por digestão e combustão seca em auto-analisador Carlo Erba NA 1500.

$\mathrm{O}$ tratamento estatístico dos dados incluiu o cálculo de médias e errospadrão das médias para as diferentes idades de pastagens, bem como da correlação de Pearson entre a biomassa microbiana, a massa de raizes finas e 0 teor de água no solo. Para os dados da EMBRAPA de 1992-1993, foram utilizadas Análises de Variância, seguidas pelo teste de Tukey, para verificar as diferenças entre os tratamentos.

\section{RESULTADOS E DISCUSSÃO}

Apesar das limitações do método de Fumigação Incubação (FI) de Jenkinson \& Polwson (1976), adaptado para solos ácidos (Vance et al., 1987), para a determinação da biomassa microbiana, ele foi utilizado por ser praticamente o único método disponivel na época em que foi iniciado o presente estudo. Considerou-se também que, por se tratar de um estudo comparativo feito em solos muito similares e locais próximos, os resultados obtidos pelo método de FI seriam válidos para os objetivos deste estudo.

\section{Efeitos de Curto Prazo na Biomassa Microbiana do Solo, Raízes e Transformações de Nitrogênio.}

Na comparação de uma pastagem de 2 anos de idade, plantada com Brachiaria humidicola, fertilizada e bem manejada, com a queimada e a floresta natural adjacentes, foram 
encontradas algumas diferenças importantes nos padrões e na composição dos parâmetros estudados entre os três sistemas de uso da terra e as duas profundidades das amostras.

As quantidades médias anuais de biomassa microbiana do solo da floresta foram cerca de duas vezes maiores na camada superficial do solo $(0-5 \mathrm{~cm})$ do que na camada de 5-20 cm (Tab. 1). Já na área queimada, as quantidades de biomassa microbiana foram maiores na camada de $5-20 \mathrm{~cm}$ do que na camada superficial. $\mathrm{O}$ decréscimo da biomassa na camada superficial e o aumento da biomassa na camada de $5-20 \mathrm{~cm}$ na área queimada foram significativos. $\mathrm{Na}$ pastagem, as quantidades de biomassa foram cerca de $60 \%$ maiores na camada superficial do solo do que na camada de 5-20 cm (Tab. 1). Quando considerada a profundidade de $0-20 \mathrm{~cm}$ como um todo, observou-se um pequeno aumento líquido na biomassa microbiana total do solo na pastagem em comparação com a floresta. As quantidades de biomassa microbiana, em termos de porcentagem do carbono total nas camadas de $0-5 \mathrm{~cm}$ e de $5-20 \mathrm{~cm}$ foram de 2,5 e $3,3 \%$ na floresta, de 1,8 e 3,9\% na área queimada, e de 3,1 e 4,3\% na pastagem (Luizâo et al., 1992b) indicando um aumento nas proporções na camada inferior (especialmente na queimada) e na pastagem, provavelmente devido à maior mineralização da matéria orgânica remanescente da floresta (Anderson \& Domsch, 1986). A biomassa microbiana foi positivamente correlacionada com as taxas de respiração em todos os três sistemas $\left(r^{2}=0,44 ; p<0,001\right)$ (Luizão et al., 1992b).

As taxas médias de respiração na camada superficial do solo (de $0-5 \mathrm{~cm}$ ) foram mais baixas na pastagem e, especialmente, na área queimada, do que nos solos de floresta (Tab. 1). As médias da taxa de respiração na camada de 5-20 $\mathrm{cm}$ foram drasticamente reduzidas nos três sistemas. Estes resultados confirmam que a maior atividade microbiana está concentrada nos primeiros centimetros superficiais do solo e é mais ativa onde a fonte/reservatório de nutrientes é maior (i.e. floresta nativa).

Há atualmente crescente evidência de que os parâmetros biológicos do solo são indicadores potencialmente sensiveis ao estresse do solo ou às

Tabela 1. Valores médios $(\mathrm{n}=6)$ da massa de raizes finas e das medidas bioquimicas do solo numa seqüência de floresta natural, área queimada e pastagem ( 2 anos) sobre Latossolo Amarelo na FUCADA.

\begin{tabular}{|c|c|c|c|c|c|c|c|c|c|c|c|c|}
\hline \multirow[b]{2}{*}{ prof. (cm) } & \multicolumn{2}{|c|}{$\begin{array}{l}\text { Raízes } \\
\mathrm{g} \mathrm{m}^{-2}\end{array}$} & \multicolumn{2}{|c|}{$\begin{array}{c}\text { Bio C } \\
\mu g \mathrm{C} \mathrm{g}^{-1}\end{array}$} & \multicolumn{2}{|c|}{$\begin{array}{l}\text { Resp. } \\
\mu \mathrm{g} C \mathrm{~g}^{-1}\end{array}$} & \multicolumn{2}{|c|}{$\begin{array}{c}\text { Carbono } \\
(\%)\end{array}$} & \multicolumn{2}{|c|}{$\begin{array}{l}\text { Pot N } \\
\mu g g^{-1}\end{array}$} & \multicolumn{2}{|c|}{$\begin{array}{c}\text { Pot } \mathrm{NO}_{3} \\
\mu \mathrm{g} \mathrm{g}{ }^{-1}\end{array}$} \\
\hline & $0-5$ & $5-20$ & $0-5$ & $5-20$ & $0-5$ & $5-20$ & $0-5$ & $5-20$ & $0-5$ & $5-20$ & $0-5$ & $5-20$ \\
\hline Floresta & 724 & 495 & 1287 & 765 & 194 & 75 & 5,2 & 2,3 & 6 & 1 & 5 & 2 \\
\hline Queimada & 518 & 852 & 829 & 933 & 110 & 67 & 4,7 & 2,4 & 7 & 9 & 6 & 5 \\
\hline Pastagem & 851 & 453 & 1290 & 806 & 159 & 53 & 4,2 & 1,9 & 6 & -1 & 2 & 2 \\
\hline
\end{tabular}

Bio $\mathrm{C}$ = biomassa microbiana do solo medida por Fumigação-Incubação; Resp = respiração do solo em amostras incubadas por 10 dias; Carbono = teor de carbono nas amostras de solo; Pot $\mathrm{N}=$ potencial de mineralizaçăo do $\mathrm{N}$ em solo incubado por 10 dias; e $\mathrm{Pot}^{\mathrm{NO}_{3}}=$ potencial de nitrificação do $\mathrm{N}$ em solo incubado por 10 dias. 
mudanças em sua produtividade (Dick \& Gupta, 1994). A despeito da existência de estudos mostrando que os teores totais de carbono em solos de pastagens são comparáveis aos da floresta original após alguns anos de cultivo (Cerri et al., 1991), pode-se supor que as formas de matéria orgânica presentes em solos de floresta natural e pastagens sejam diferentes, e que a forma lábil, representada pela biomassa microbiana do solo, possa ser substanciaImente diferente sob as duas situações. Neste estudo, isto é evidenciado pelas medidas das taxas de transformação do nitrogênio. Embora, tanto a biomassa-C quanto a atividade microbiana (respiração) tenham sido drasticamente reduzidas na área queimada, não houve conseqüências significativas sobre as taxas de mineralização e nitrificação nesse solo, cujos valores foram muito similares aos da floresta original (Tab. 1). Luizão et al. (1992b) mostraram que após a queima, a composição do $\mathrm{N}$ mineral desse solo, que na floresta é predominantemente formado por N$\mathrm{NH}_{4}^{+}(>90 \%)$ mudou, em ambas as profundidades, para $60 \%$ de $\mathrm{NO}_{3}^{-}$. Essa mudança na composição do $\mathrm{N}$-mineral sugere que a queimada propiciou a proliferação de um grupo de microrganismos no solo, as bactérias nitrificantes, cuja ação manteve as taxas de transformação do nitrogênio nos mesmos níveis da floresta.

Os valores negativos encontrados para os potenciais de mineralização de $\mathrm{N}$ e de nitrificação (Tabs. 1, 3 e 4) indicam ter havido uma imobilização do $\mathrm{N}$ do solo pela biomassa microbiana
(Alexander, 1977). Não havendo liberação de $\mathrm{N}$ em quantidades acima das que haviam no solo antes da incubação por 10 dias, os potenciais de mineralização de $\mathrm{N}$ e de nitrificação podem tornar-se negativos, uma vez que correspondem à diferença entre o $\mathrm{N}$ produzido na incubação e o que havia antes no solo.

Também para a quantidade de raizes finas nas camadas superiores do solo foi detectada uma mudança causada pela conversão da floresta em pastagem. A massa total de raízes nos primeiros $20 \mathrm{~cm}$ do solo diminuiu drasticamente com a instalação da pastagem (Tab. 2). Maiores quantidades de raizes, especialmente das finas (diâmetro inferior a $1 \mathrm{~mm}$ ), foram encontradas em abril, durante a estação chuvosa, tanto na floresta quanto na pastagem, enquanto que as menores quantidades delas foram medidas em outubro, durante a estação seca. As grandes diferenças em massa encontradas entre as duas estações indicam uma alta taxa de renovação das raizes finas e, conseqüentemente, do carbono e dos nutrientes nelas contidos, em ambas as áreas, porém mais acentuadamente na pastagem de 2 anos. As quantidades totais e as taxas de renovação das raizes finas na camada superior de $0-5 \mathrm{~cm}$ do solo seriam comparáveis e de importância similar à da liteira fina da floresta (Luizão et al. 1992a). A importância relativa das raízes finas é maior na pastagem de 2 anos do que na floresta, sugerindo que a rápida renovação da raízes finas na pastagem (Luizão et al. 1992a) é um fator-chave para a recuperação dos niveis de matéria orgânica do solo após o desmatamento, juntamente com a rápida 
decomposição e liberação do carbono da liteira das gramíneas (F. J. Luizão, dados não-publicados).

A concentração de $\mathrm{C}$ nas raizes (de todos diâmetros) encontradas na camada de 0-5 cm (onde, na pastagem, predominam as raizes finas da gramínea) foi geralmente menor do que na camada inferior, de 5-20 cm (Tab. 2). As raízes da pastagem apresentaram os menores teores de carbono e nitrogênio, especialmente as finas, que devem ser originárias da gramínea Brachiaria humidicola. A relação $\mathrm{C} / \mathrm{N}$ das raízes finas foi também maior na pastagem do que na floresta madura. Isto pode indicar a formação, pela gramínea da pastagem, de uma matéria orgânica de qualidade inferior à originalmente produzida pela floresta.

\section{Dinâmica da Biomassa Microbiana e do Nitrogênio do Solo em Diferentes Idades das Pastagens}

$\mathrm{Na}$ seqüência de idades das pastagens estudadas (de 2 a 13 anos), foi observado um incremento da biomassa microbiana e respiração na camada superficial de $0-5 \mathrm{~cm}$ até os cinco anos após o estabelecimento da pastagem, seguido por um declinio progressivo, que se acentua após o oitavo ano da pastagem (Tab. 3). As maiores quantidades de biomassa microbiana e da respiração do solo na pastagem de 5 anos deve ser uma conseqüência tanto das fertilizações aplicadas no primeiro ano, quanto da menor compactação relativa do solo resultante do sistema de rodizio no pastejo do gado. Por outro lado, os solos das pastagens de 12 e 13 anos, mais compactadas, mostraram condições menos favoráveis para o desenvolvimento da biomassa microbiana. Na pastagem de 12 anos, a quantidade de raizes finas foi menor do que nas pastagens mais jovens e o teor de carbono orgânico foi substancialmente reduzido, o que pode ter contribuído para o declínio na biomassa microbiana. Nas medidas efetuadas em 1990, a biomassa de raízes foi mais de três vezes maior na pastagem de 5 anos $\left(1112 \mathrm{~g}, \mathrm{~m}^{-2}\right)$ do que nas pastagens de 7 e 12 anos (361 g. $\mathrm{m}^{-2}$ e $243 \mathrm{~g} . \mathrm{m}^{-2}$, respectivamente). A

Tabela 2. Massa de raizes $\left(\mathrm{g} \mathrm{m}^{-2}\right)$ e teor médio de carbono (\%), nitrogênio (\%), e relação $\mathrm{C} / \mathrm{N}$ nas diferentes classes de raizes nas camadas superiores do solo em floresta natural, área queimada e pastagem jovem (2 anos) sobre Latossolo Amarelo na FUCADA. Os valores são as médias de seis amostras compostas (misturando-se as raizes das quatro coletas feitas ao longo de um ano).

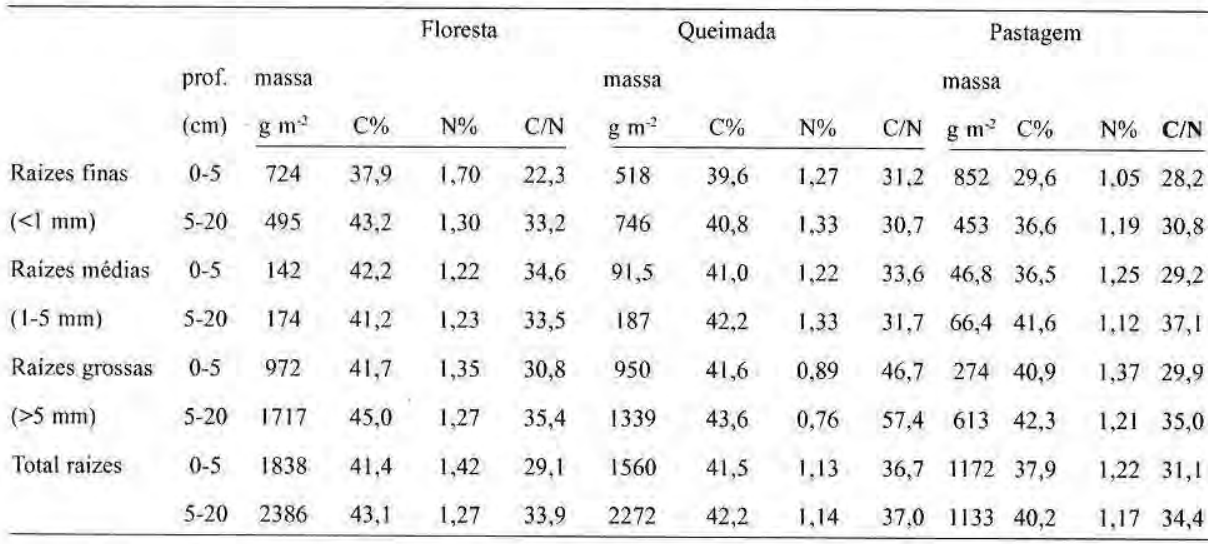


biomassa de raízes finas medidas foi positivamente correlacionada $(\mathrm{r}=$ 0,782 ) com a biomassa microbiana do solo e com o teor de água no solo, indicando que as raizes e a umidade do solo são fatores fundamentais para definir o tamanho da população microbiana no solo.

O nitrogênio mineral foi encontrado predominantemente na forma de amônio, especialmente nas medidas efetuadas na estação seca, quando o $\mathrm{N}^{-\mathrm{NH}^{+}}{ }_{4}$ representou $96 \%$ do $\mathrm{N}$-mineral na pastagem de 5 anos, fertilizada, 77\% na pastagem de 12 anos, e $59 \%$ na pastagem de 8 anos. A diminuição das taxas de transformações do nitrogênio mesmo quando a disponibilidade de nitrogênio mineral no solo não é baixa (Tab. 3), sugere que está havendo maior demanda de nitrogênio pelas plantas e biota do solo. Este fenômeno indica um declínio no estoque de nitrogênio orgânico do solo, o que eventualmente leva à defíciência de $\mathrm{N}$ nas pastagens mais velhas.

\section{Recuperação das Propriedades Bioquímicas do Solo após Abandono das Pastagens}

Na sequência pastagem abandonadapousio de 5 anos-floresta, estudadas na estação seca, na transição e na estação chuvosa, o carbono orgânico no solo da camada de $0-10 \mathrm{~cm}$ apresentou as menores concentrações médias nos solos da pastagem abandonada há 1,5 anos, em todas as estações (média de 2,99\%). Conforme esperado, o solo do pousio apresentou valores intermediários $(3,28 \%)$, enquanto que o solo de floresta apresentou as maiores concentrações de carbono orgânico $(3,82 \%)$. Na estação seca, a biomassa microbiana na floresta $\left(1526 \mu \mathrm{g} \mathrm{C} \mathrm{g}^{-1}\right)$ foi significativamente maior (ANOVA; $\mathrm{F}=10,0 ; \mathrm{p}<$ $0,01)$ do que em ambas, pastagem

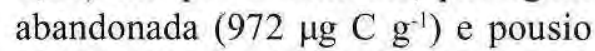
$\left(1024 \mu \mathrm{g} \mathrm{C} \mathrm{g}^{-1}\right)$ sendo que estes apresentaram valores próximos entre $\mathrm{si}$ (Tab. 4). No periodo de transição entre as estações, a biomassa microbiana do

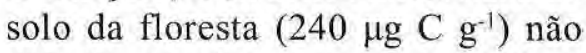
diferiu significativamente das duas outras áreas (183 e $216 \mu \mathrm{g} \mathrm{C} \mathrm{g}^{-1}$ para pastagem e pousio, respectivamente), notando-se um declínio acentuado na biomassa microbiana do solo da pastagem, do pousio e da floresta (Costa, 1993) em relação às outras estações. Tanto na estação seca quanto no período de transição ou na estação chuvosa, as medidas de respiração do solo seguiram os mesmos padrões mostrados pela biomassa microbiana nos três ecossistemas, com as médias do solo de floresta apresentando valores muito maiores do que as outras duas áreas (Tab. 4). No entanto, na estação chuvosa, houve uma forte diminuição da atividade microbiana (respiração) no solo da floresta, resultando em valores próximos, e não significativamente diferentes, dos obtidos no pousio.

Mesmo após cinco anos de pousio, a biomassa-C desse solo ainda foi similar à da pastagem abandonada. No entanto, no pousio, a população microbiana mostrou ser mais ativa, tanto na mineralização do carbono, medido como respiração do solo, como na mineralização do nitrogênio. Isto ocorreu especialmente em relação à nitrificação, cujos valores foram 
Tabela 3. Resultados médios ( $\mathrm{n}=6)$ das medidas bioquimicas do solo numa seqüência de pastagens de diferentes idades $(2,5,6,7,8,12$ e 13 anos) sobre Latossolo Amarelo na FUCADA e na EMBRAPA. Os valores entre parênteses correspondem aos erros-padrão das médias.

\begin{tabular}{|c|c|c|c|c|c|c|c|c|c|c|c|c|c|c|}
\hline \multirow[b]{2}{*}{$\begin{array}{l}\text { Prof. } \\
\text { (cm) }\end{array}$} & \multicolumn{2}{|c|}{$\begin{array}{c}\text { Bio C } \\
\mu g \mathrm{C} \mathrm{g}^{-1} \\
\end{array}$} & \multicolumn{2}{|c|}{$\begin{array}{c}\text { Resp. } \\
\mu g \mathrm{C}^{-1}\end{array}$} & \multicolumn{2}{|c|}{$\begin{array}{c}\mathrm{NH}^{+}{ }_{4} \\
\mu \mathrm{g} \mathrm{N} \mathbf{g}^{-1}\end{array}$} & \multicolumn{2}{|c|}{$\begin{array}{c}\mathrm{NO}_{3} \\
\mu \mathrm{g} \mathrm{N} \mathrm{g}^{-1}\end{array}$} & \multicolumn{2}{|c|}{$\begin{array}{c}\mathrm{N}-\text { mineral } \\
\mu \mathrm{g} \mathrm{N} \mathrm{g}^{-1}\end{array}$} & \multicolumn{2}{|c|}{$\begin{array}{c}\text { Pot } N \\
\mu g \text { N g }^{-1}\end{array}$} & \multicolumn{2}{|c|}{$\begin{array}{l}\text { Pot } \mathrm{NO}_{3} \\
\mu \mathrm{N} \mathrm{g}^{-1}\end{array}$} \\
\hline & $0-5$ & $5-20$ & $0-5$ & $5-20$ & $0-5$ & $5-20$ & $0-5$ & $5-20$ & $0-5$ & $5-20$ & $0-5$ & $5-20$ & $0-5$ & $5-20$ \\
\hline \multirow[t]{2}{*}{2 anos } & 1290 & 806 & 159 & 53 & 20,1 & 28,7 & 3,67 & 3,28 & 23,8 & 32,0 & 4,0 & 2,8 & 4,6 & 1,8 \\
\hline & $( \pm 5,01)$ & $( \pm 5,55)$ & $( \pm 2,04)$ & $( \pm 1,39)$ & $( \pm 1,39)$ & $( \pm 1,56)$ & $( \pm 0,40)$ & $( \pm 0,37)$ & $( \pm 1,43)$ & $( \pm 1,58)$ & $( \pm 0,46)$ & $( \pm-2,76)$ & $( \pm 0,58)$ & $( \pm 0,66)$ \\
\hline \multirow[t]{2}{*}{6 anos } & 1390 & 594 & 224 & 52 & 7,42 & 2,08 & 1,19 & 0,93 & 8,6 & 3,01 & $-2,4$ & 0.56 & 0,61 & 0,56 \\
\hline & $( \pm 8,07)$ & $( \pm 6,65)$ & $( \pm 0,81)$ & $( \pm 1,94)$ & $( \pm 0,59)$ & $( \pm 0,54)$ & $( \pm 0,39)$ & $( \pm 0,16)$ & $( \pm 0,89)$ & $( \pm 0,62)$ & $( \pm 1,36)$ & $( \pm 0,14)$ & $( \pm 0,34)$ & $( \pm 0,14)$ \\
\hline \multirow[t]{2}{*}{7 anos } & 1154 & 1073 & 221 & 82 & 11,4 & 7,35 & 9,80 & 1,89 & 21,2 & 9,24 & $-2,2$ & 1,4 & 4,43 & 4,96 \\
\hline & $( \pm 9,20)$ & $( \pm 6,24)$ & $( \pm 3,62)$ & $( \pm 1,55)$ & $( \pm 1,94)$ & $( \pm 0,75)$ & $( \pm 3,16)$ & $( \pm 0,49)$ & $( \pm 4,38)$ & $( \pm 0,64)$ & $( \pm 5.93)$ & $( \pm 1,82)$ & $( \pm 4,73)$ & $( \pm 1,72)$ \\
\hline 12 anos & $( \pm 4.65)$ & $( \pm 3,1)$ & $( \pm 3,20)$ & $( \pm 1,88)$ & $( \pm 1,63)$ & $( \pm 0,0)$ & $( \pm 0,61)$ & $( \pm 1,41)$ & $( \pm 1,80)$ & $( \pm 1,41)$ & $( \pm 0,45)$ & $( \pm 1,04)$ & $( \pm 1,26)$ & $( \pm 1,16)$ \\
\hline \multirow[t]{2}{*}{13 anos } & 612 & 400 & 81 & 32 & 7,30 & 5,71 & 3,90 & 3,70 & 11,2 & 9,4 & $-2,3$ & 1,4 & 0,49 & 1,7 \\
\hline & $( \pm 5,67$ & $( \pm 4,06)$ & $( \pm 3,41)$ & $( \pm 2,19)$ & $( \pm 0,26)$ & $( \pm 0,53)$ & $( \pm 0,74)$ & $( \pm 0,77)$ & $( \pm 0,90)$ & $( \pm 0,98)$ & $( \pm 0,65)$ & $( \pm 0,63)$ & $( \pm 0,27)$ & $( \pm 0,36)$ \\
\hline
\end{tabular}

Bio $\mathrm{C}=$ biomassa microbiana do solo medida por Fumigação-Incubação; Resp = respiração do solo em amostras incubadas por 10 dias; Pot $\mathrm{N}=$ potencial de mineralização do $\mathrm{N}$ em solo incubado por 10 dias; Pot $\mathrm{NO}_{3}=$ potencial de nitrificação do $\mathrm{N}$ em solo incubado por 10 dias, $\mathrm{NH}_{4}^{+}=\mathrm{N}^{-a m o ̂ n i o ~ e ~} \mathrm{NO}_{3}=$ nitrato do solo não-incubado 
Tabela 4. Sumário dos resultados das medidas bioquimicas dó solo numa sequêencia pastagem abandonada pousio - floresta natural sobre Latossolo Amarelo na EMBRAPA. Os valores são as médias de cinco amostras compostas e das três coletas realizadas (estação seca, transição e chuvosa).

\begin{tabular}{|c|c|c|c|c|c|c|c|c|}
\hline prof $(0-10)$ & $\frac{\text { Bio } C}{\mu g C g^{-1}}$ & 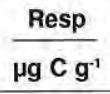 & $\frac{\text { Carbono }}{(\%)}$ & $\begin{array}{c}\mathrm{NH}_{4} \\
\mu \mathrm{g} \mathrm{N} \mathrm{g}{ }^{-1}\end{array}$ & $\begin{array}{c}\mathrm{NO}_{3} \\
\mu \mathrm{g} \mathrm{N} \mathrm{g}{ }^{-1}\end{array}$ & $\begin{array}{l}\mathrm{N} \text { min. } \\
\mu \mathrm{g} \mathrm{N} \mathrm{g}^{-1}\end{array}$ & $\begin{array}{c}\text { Pot } N \\
\mu g \mathrm{~N} \mathrm{~g}^{-1}\end{array}$ & $\begin{array}{l}\text { Pot } \mathrm{NO}_{3} \\
\mu \mathrm{g} \mathrm{N} \mathrm{g}^{-1}\end{array}$ \\
\hline Past. aband. & 552 & 81 & 2,99 & 22 & 19 & 24 & -18 & -2 \\
\hline Pousio & 553 & 104 & 3,28 & 14 & 12 & 26 & 29 & 20 \\
\hline Floresta & 795 & 186 & 3,82 & 11 & 4 & 35 & 32 & 4 \\
\hline
\end{tabular}

Bio $\mathrm{C}=$ biomassa microbiana do solo medida por Fumigação-Incubação; Resp = respiraçăo do solo em amostras incubadas por 10 dias; Carbono = teor de carbono nas amostras de solo; $\mathrm{N}$ min = nitrogênio mineral no solo; Pot $\mathrm{N}=$ potencial de mineralização do $\mathrm{N}$ em 10 dias; $\mathrm{Pot} \mathrm{NO}_{3}=$ potencial de nitrificação do $\mathrm{N}$ em 10 dias.

similares aos medidos no solo da floresta. Esses resultados indiretamente confirmam haver ocorrido uma mudança nos grupos taxonômicos que compõem a biomassa microbiana, à medida que foram alteradas as condições físicas, químicas e nutricionais do solo, favorecendo, aparentemente, os organismos nitrificantes.

Assim, em termos de população microbiana, sua atividade e de sua intermediação na dinâmica do carbono e nitrogênio, a floresta geralmente apresentou os maiores valores, mas a área de pousio já apresenta sinais de recuperação do solo, mostrando, para os parâmetros acima estudados, valores intermediários aos obtidos na floresta natural e na pastagem abandonada. A recuperação de algumas características biológicas e bioquímicas do solo pode ser atribuída a diversos fatores, entre os quais: i) a variedade de plantas invasoras que se desenvolvem nas pastagens degradadas, pertencendo a famílias como Leguminosae, Bignoniaceae, Gramineae, Compositae, Solanaceae e outras. Estas plantas, com sistemas radiculares estruturalmente diversificados, promovem melhor aeração e oxigenação do solo (Grimaldi et al., 1992), cuja maior conseqüência é o incremento da atividade biológica e a descompactação do solo; ii) a diversidade de plantas influencia qualitativa e quantitativamente a entrada de nutrientes no solo, através da liteira produzida pelas diferentes espécies vegetais.

As baixas taxas de mineralização do nitrogênio no solo sugerem que o estoque de N orgânico está diminuindo, o que pode levar à deficiência de nitrogênio nas pastagens mais velhas.

O periodo de cinco anos é ainda curto para recuperar o solo da pastagem usada moderadamente por cerca de 4 anos para pastejo e depois deixada para pousio. O solo do pousio apresentou grande variabilidade nos parâmetros medidos, caracterizando a existência de mosaicos de micro-sítios, alguns com características mais recuperadas e similares às da floresta, misturados a outros com solo ainda muito compactado e com pouca atividade bioquímica.

O manejo da cobertura do solo com forrageiras (leguminosas ou mesmo gramíneas diferentes) poderiam, pela produção de raizes, exudatos e liteira, apressar a restruturação e recuperação do solo nas áreas de pastagens degradadas num prazo mais curto, permitindo o seu reaproveitamento como pastagem ou a 
formação de um sistema agro-florestal, talvez usando parte da própria vegetação secundária (Luizão \& Luizão, 1991). Em qualquer dos casos, novas derrubadas de floresta original poderiam ser evitadas.

\section{CONCLUSÕES}

Nos ecossistemas de pastagens implantadas sobre Latossolos Amarelos originalmente cobertos por floresta tropical densa, há uma recuperação relativamente rápida do conteúdo total de carbono no solo, poucos anos após a derruba e queima da floresta (Cerri et al., 1991). Isto ocorre principalmente em pastagens bem manejadas e tem sido comumente atribuído à decomposição do material morto remanescente da floresta original (troncos, galhos e resíduos sobre o solo), mas poderia ser, em grande parte, também o resultado da rápida decomposição de ambos, da liteira das gramíneas da pastagem, bem como de suas raizes, especialmente das mais finas, de rápida renovação (Luizão et al., 1992). No entanto, alguns outros aspectos da questão devem ser igualmente observados, tais como:

i) o teor (e possivelmente a qualidade) de carbono de ambos, liteira e raízes das gramíneas, é menor que a dos materiais de mesma natureza derivados da floresta. Estudos recentes demonstram que tanto o conteúdo como a disponibilidade de nutrientes da nova matéria orgânica produzida pelas pastagens são inferiores aos da floresta original (EEC, 1994). Isto poderia ser em grande parte atribuido ao fato que as maiores fontes de matéria orgânica para o solo da pastagem são a liteira e as raizes das gramíneas, ambos relativamente pobres em carbono e nutrientes (F. J. Luizão, dados nãopublicados); também porque em pastagens velhas, acima de 12 anos de uso, como confirmado neste estudo, um decréscimo acentuado no carbono orgânico do solo pode ser observado.

Desta forma, práticas de manejo da produção e da deposição da liteira e o uso de espécies vegetais que produzam, não apenas grande quantidade de liteira diversificada, como também uma abundância de raizes nas camadas superiores do solo, devem ser incentivadas para um uso mais sustentado dos Latossolos Amarelos argilosos da Amazônia Central. Isto é necessário para manter os contínuos processos de reciclagem da matéria orgânica e dos nutrientes, mas especialmente para manter em funcionamento o sistema biológico das camadas superiores numa maneira o mais similar possivel àquela dos ecossistemas naturais.

\section{AGRADECIMENTOS}

Os autores agradecem o auxílio financeiro do CNPq (Proc. $n^{2} 500683 /$ 90-5) e dos Projetos Amazônia I SAREC e CEE/TS 22-031C (INPA/ CENA/ORSTOM); à EMBRAPA e à FUCADA, pelo uso das áreas de estudo; à Cilene Palheta e aos bolsistas de Iniciação Científica e Aperfeiçoamento do $\mathrm{CNPq}$ que contribuíram na realização deste estudo.

\section{Bibliografia citada}

Alexander, M. 1977. Introduction to soil microbiology. John Wiley \& Sons, Inc. 472p.

Anderson, T. H.; Domsch, K. H. 1986. Carbon link between microbial biomass and soil 
organic matter. International Symposium in Microbial Ecology, pp 467-471.

Bonde, T. A.; Schnürer, J. Rosswall T. 1988. Microbial biomass as a fraction of potentially mineralizable nitrogen in soils from long-term field experiments. Soîl Biology \& Biochemistry, 20: 447-452.

Brookes, P, C.; Landman, A.; Pruden, G.; Jenkinson, D. S. 1985. Cloroform fumigation and the release of soil nitrogen: a rapid direct extraction method for microbial biomass nitrogen in soil. Soil Biology \& Biochemistry, 17: 837-842.

Brookes, P. C.; Verstraete, W. 1989. The functioning of soil as an ecosystem. In: Soil quality assessment. State of the art report on soil quality. Report to Commission of the European Communities Directorate-General XII, Contract EV4A/0008 NL, Brussels.

Cerri, C. C.; Volkoff, B;; Andreaux, F. 1991. Nature and behaviour of organic matter in soils under natural forest, and after deforestation, burning and cultivation, near Manaus. Forest Ecology \& Management, 38: 259-271.

Correa, J. C.; Reichardt, K. 1989. The spatial variability of Amazonian soils under natural forest and pasture. GeoJournal, 19 (4): 423-427.

Costa, E. S. 1993. Aspectos biogeoquímicos do carbono, nitrogênio e fósforo em latossolos num gradiente de regeneração natural de uma pastagem abandonada na Amazônia Central. Monografia CEPF/UTAM, 66p.

Dick, R. P.; Gupta, V. V. S. R. 1994. A conceptual model for the role of abiotic soil enzymes in microbial ecology: a potential analogue for soil quality. In: Pankhurst, C. E.; Doube B. M.; Gupta, V. V. S. R.; Grace, P. R. (eds), Soil Biota: Management in Sustainable Farming Systems, Commonwealth Scientific and Industrial Research Organization (CSIRO), Australia, pp. 167-168.

EEC. 1994. Dynamics of soil organic matter in the Amazon ecosystem and after deforestation: bases for efficient agricultural management. Final Report. INPA/CENA-USP/ORSTOM/ CNRS-CPB/CSIC. Bruxelas, 130p.

Fearnside, P. M. 1989. Deforestation in Brazilian Amazon: The rates and causes of forest destruction. The Ecologist, 19: 214-218.

Giné, M. F.; Bergamin Filho, H.; Zagatto, E. A. G.; Reis, B. F. 1980. Simultaneous determination of nitrate and nitrite by flow injection analysis. Analitica Chimica Acta, 114: 192-197.

Grimaldi, M.; Sarrazin, M.; Chauvel, A.; Luizão, F.; Rodrigues, M. R. 1992. Efeitos da vegetação e da ação do homem sobre a estrutura dos Latossolos argilosos da Amazônia brasileira. Annals of the First International Symposium on Enviromental Studies in Tropical Rain Forests, Biosfera, Rio de Janeiro, pp. 25-29.

Herrera, R.; Jordan, C. F.; Klinge, H.; Medina, E. 1978. Amazon ecosystems: their structure and functioning with particular emphasis on nutrients. Interciencia, 3: 223-232.

Jenkinson, D. S.; Ladd, J. N. 1981. Microbial biomass in soil: measurements and turnover. Soil Biology \& Biochemistry, 5: 415-471.

Jenkinson, D. S.; Powlson, D. S. 1976a. The effects of biocidal treatments on metabolism in soil. I. Fumigation with chloroform. Soil Biology \& Biochemistry, 8: 167-177.

Jenkinson, D. S.; Powlson, D. S. 1976b The effects of biocidal treatments on metabolism in soil. II. Gama irradiation, autoclaving, air drying and fumigation with chloroform or methylbromide. Soil Biology \& Biochemistry, 8: 179-188.

Jordan, C. F. 1985. Nutrient cycling in tropical forest ecosystems: principles and their application in management and conservation. John Wiley \& Sons Ltd,. 190p.

Luizão, F.; Luizão, R.; Chauvel, A. 1992a. Premiers résultats sur la dynamique des biomasses racinaires et microbiennes dans un latosol d'Amazonie centrale (Brésil) sous forêt et sous pâturage. Cahiers ORSTOM, sér, Pédol, 27: 69-79.

Luizão, R. C. C.; Bonde, T. A.; Rosswall, T. $1992 b$. Seasonal variation of soil microbial biomass - the effects of clear-felling a tropical forest and establishment of pasture in the Central Amazon. Soil Biology \& Biochemistry, 24: 805-813.

Luizão, R. C. C.; Luizão, F. J. 1991. Liteira e biomassa microbiana do solo no ciclo da 
matéria orgânica e nutrientes em terra firme na Amazônia Central. In: Val, A.. L.; Figliuolo, R.; Feldberg, E. (eds.). Bases Cientificas para Estratégias de Preservação e Desenvolvimento da Amazonia: Fatos e Perspectivas. Secretaria de Ciência e Tecnologia/INPA, Manaus - AM, Vol.1, pp. 239-249.

Pires, J. M; Prance, G. T. 1985. The vegetation types of the Brasilian Amazon. In: Prance, G. T.; Lovejoy, T. E. (eds.). Key Environments: Amazonia, Pergamon Press, Oxford, pp.109-145.

Powlson, D. S.; Brookes, P. C.; Christensen, B. T.1987. Measurement of soil microbial biomass provides an early indication of changes in total soil organic matter due to straw incorporation. Soil Biology \& Biochemistry, 19:159-164.

Ribeiro, M. N. G.; Adis, J. 1984. Local rainfall variability - a potencial bias for bioecological studies in the Central Amazon. Acta Amazonica, 14: 159-174.
Saggar, S.; Bettany J. R.; Stewart, J. W. B. 1981. Measurement of microbial sulphur in soils. Soil Biology \& Biochemistry, 13: 335-341.

Schubart, H. O. R.; Franken, W.; Luizão, F. J. 1984. Uma floresta sobre solos pobres. Ciência Hoje, 2: 26-32.

Singh, K. P. 1968 Litter production and nutrient turnover in deciduous forest of Varanasi. Proceedings of the Symposium on Recent Advances in Tropical Ecology, pp. 655-665.

Teixeira, L. B.; Bastos, J. B. 1989. Nutrientes nos solos de floresta pimária e pastagem de Brachiaria humidicola na Amazônia Central. Boletim de Pesquisas EMBRAPA/ CPATU, $\mathrm{n}^{2} .98,31 \mathrm{p}$.

Vance, E. D.; Brookes, P. C.; Jenkinson, D. S. 1987. Microbial biomass measurements in forest soils: the use of the chloroform fumigation-incubation method for strongly acid soil. Soil Biology \& Biochemistry 19: 697-702. 